Title: Teaching about bioethics through authoring of websites

Christopher J.R. Willmott ${ }^{1^{*}}$ and Jane Wellens ${ }^{2}$

${ }^{1}$ Department of Biochemistry and ${ }^{2}$ Teaching and Learning Unit, University of Leicester, University

Road, Leicester, LE1 7RH

* Corresponding author (Chris Willmott)

Telephone: 0116 2522094/2523471

Fax: 01162523369

E-mail: cjrw2@le.ac.uk

Running title: teaching bioethics through web authoring

Key words: ethics, web, bioethics, peer review

Brief description: An evaluation of the impact of a novel exercise using web authoring to teach about bioethics

Classification of manuscript: "Practical paper" 


\title{
Title: Teaching about bioethics through authoring of websites
}

\author{
ABSTRACT \\ There is growing awareness of the importance of equipping students with the abilities to think \\ through the ethical implications of developments in biology. We describe an exercise in which \\ students work in teams to produce websites about current controversial issues within the subject. \\ Participants report improvement in their knowledge of bioethics. Additionally, we note not only a \\ broadening of their awareness of such issues, but also an increase in their use of appropriate \\ scientific terminology. This web authoring activity could readily be adapted for use with students \\ in a broader range of disciplines at both tertiary and secondary level.
}




\section{INTRODUCTION}

The frequency with which bioethical stories reach the front page of both the quality and popular newspapers is an indication of the increasing impact new biological and medical techniques are having upon the wider society. Many undergraduate programmes in the biosciences have traditionally neglected discussion of the wider impact and ethics of the subject. In the UK, the importance of enhancing the ethical dimension of biological education has been recognised by the Quality Assurance Agency (QAA), the body charged with safeguarding standards in higher education. Between 2000 and 2002, the QAA published benchmarking documentation for different subject areas designed to "make explicit the general academic characteristics and standards of honours degrees in the UK" (QAA, 2002). The benchmarking statements for bioscience included nine recommendations pertaining to the ethics of biology. These included the suggestion that all students should "Have some understanding of ethical issues and the impact on society of advances in the biosciences" and that good students should "Be able to construct reasoned arguments to support their position on the ethical and social impact of advances in the biosciences".

Here we describe an exercise in which Second Year undergraduates engage with ethical issues by authoring web sites about current controversial developments. In addition to increasing their awareness of the ethical dimension of their subject, students also develop a range of generic skills, including teamwork and an ability to produce web pages..

\section{METHODOLOGY}

Description of activity: The exercise described below has been incorporated as an aspect of a Second Year undergraduate module "Targeting Biochemical Knowledge to Medical Problems". The module is compulsory for students on our Medical Biochemistry programme (approximately 30 students per year) and is also offered to Medical students as one of their optional Special Study Modules, with approximately 7 students per year electing to take this course. The learning 
outcomes of the activity are given in Table 1. From this list it will be clear that there are consciously two main goals of this task. Firstly, there is the intention to deepen the students' understanding of the science and ethical considerations associated with a current development in biomedicine. Secondly, a number of transferable skills are addressed, including the ability to work as a team, the ability to produce web pages and an important but sometimes overlooked skill, namely the ability to recognise that not all of the material published on the web is equally authoritative or accurate.

At the core of this exercise, the students work in teams of four or five to produce a set of web pages on a specific bioethical topic. They are advised that although they may draw on whatever information is available in textbooks, journals and other printed media, their primary task is to produce a website that reviews other web-based materials on their specified topic (see below). Furthermore, they are instructed that their pages should include a background briefing on the science underlying the issue and should fairly reflect the diversity of informed ethical opinion on the topic. In addition to this, each team is required to give a short presentation about their topic to their peers and the course staff.

Few of the students had any previous experience of producing web pages; only 3 out of 35 students in 2002 and 8 out of 37 in 2003 reported that they had any prior experience of web authoring. We therefore began with an introductory lecture and a workshop in which the participants are asked to produce a mini-web of four pages. Various design parameters were set down for this exercise, including an ability to make links to pages within their own web (relative links) and links to external pages elsewhere on the worldwide web (absolute links). The students were also required to import text and images from the briefing documents, which was therefore provided to them as an email attachment (a copy is currently posted on the web at www.le.ac.uk/by/cjrw2/archive/webtraining.doc). Local regulations require any web pages to be 
uploaded to the University server by an authorised member of staff, and the final section of the training therefore explained how to compress a web folder in order to send it as an attachment, which was also the preferred method for the submission of final projects. Student feedback on this exercise has been extremely positive (see Box 1).

Selection of topics and assignment to groups: Students were not given free choice in the formation of teams, but were instead allocated to groups of four or five. Although the participants were not told about the criteria used, the teams were, in fact, selected to have an even distribution of both gender and biochemical knowledge, as judged by their performance in a first semester module in Year 2. The topics were then assigned randomly to the teams by the drawing of lots. Given the context in which this activity is undertaken (see above), the topics offered for the projects were focussed on developments in molecular and cellular biology with current or near-future relevance to medical practice. The topics offered most recently are listed in Table 2. For students pursuing different Biology courses, the focus could easily be switched to, for example, use of GM technology in plants, the rights and wrongs of species introduction, or more long-standing areas of biomedical controversy such as abortion and euthanasia.

Details of assessed exercise: Having been organised into groups, the students were given six weeks to prepare a series of web pages on their assigned topic. The teams were briefed to ensure that their web reviewed at least ten other online resources relating to their topic, with the expectation that they would need to have investigated a larger number in order to decide upon a 'best ten'. It was stressed that their list of reviewed sites must appropriately reflect the diversity of informed ethical opinion on the subject. In other words, whilst there was no need to evaluate 'crank' sites, it was nonetheless important that as part of the exercise the students appreciated that different people taking a rational and measured look at the same topic can legitimately come to different conclusions. 
As part of their review process, teams had to devise a suitable rating system based on criteria of their own choice. In practice, most groups elected to assess several different features of each site, including issues such as ease of navigation, authority of content, readability and design. In addition to the review component, the students' websites were required to include adequate background information on the science behind the ethical dilemma, such that another user coming to their site would be sufficiently briefed to follow the linked pages. They were recommended to make the content suitable for their peers in teams working on other topics.

The groups were encouraged to consider the diversity of roles that individuals within their team would need to play, including: researching potential sites; deciding on review criteria; reviewing sites; designing their site, including visual appearance and navigation; and implementation of the design. They were also reminded that their completed sites would need to be delivered to the relevant member of staff for uploading onto the University server, in good time for it to be operational during the final presentations. These presentations, each fifteen minutes in length, were to introduce staff and peers to the ethical arguments for and against their controversial topic, drawing information from their own site and linked resources, as appropriate.

Assessment of students: Students were assessed on both the production of the website and the presentation. The division of marks between these two components was $66 \%$ and $34 \%$ respectively. The talks were evaluated by three members of staff and the websites by two staff. A variety of criteria were considered, including factual accuracy of content, appropriateness of reviews and scoring systems and the design and navigation of the students' own website.

The marks for the talk and the website were then combined to produce an initial team score as a percentage. Given, however, that this was a team exercise and not all members will have 
contributed equally to the process, we gave students the opportunity to assess the relative input made by members of their team, including themselves. The criteria used here were: input of ideas \& suggestions; leadership \& help in organising the work; visual design of web pages; design of navigation; design of scoring system; writing of original material (e.g. introduction); authoring/entering information into computer; and final presentation (preparation \& delivery). The peer assessments were carried out individually, under exam conditions, to negate as far as possible any collusion between team members.

Using the system developed by Conway et al (1993), these peer assessments were then used to scale the original staff mark for the team to produce final marks for individual students. In essence, the weighting process works as follows; all members of a team rate the contribution made by individuals as a score out of 5 in each of the categories outlined above. A grand total (all scores for all students added together) and an individual's total (the sum of their scores as awarded by all team members, including themselves) can then be calculated. By dividing the grand total by the number of students in the team, it is possible to work out the average mark for an individual in that team. Dividing the individual's total by the team average will then give a number a little over or a little under one. This is the relative contribution made by that individual to the overall team performance, as judged by the team themselves. When this figure is multiplied by the team score awarded by the staff, it produces the final individual mark for each student. Feedback to the students included staff comments and suggestions regarding both the website and the presentation, the team mark, the scaling factor (as described) and their final individual mark. This mark represented $20 \%$ of their assessment mark for this module.

\section{RESULTS}

Evaluation of the exercise by students: All participants were invited to fill in a questionnaire before and after this project. Firstly, they were asked to rate out of a maximum of ten marks their 
knowledge about bioethics, their interest in bioethics and their interest in being able to produce websites. A summary of these findings is given in Table 3. Secondly, they were asked to list up to ten "bioethics issues" of which they were aware. The synopsis of these findings is given in Tables 4 and 5.

When asked at the end of the exercise how able, on a scale up to 10, they felt to produce websites, the average score was 7.1 (6.8 in 2002, 7.3 in 2003). This is an encouraging figure, since only 11 out of 72 students reported any prior experience of web authoring. Additionally, the participants rated the usefulness of the exercise at 6.8 out of 10 (6.6 in 2002 and 7.0 in 2003) and their enjoyment of the task at 6.2 out of 10 (6.0 in 2002, 6.4 in 2003). No students reported a lower knowledge of bioethics after the exercise than they had initially, though one student scored their knowledge the same after the activity as they had in the a priori self-assessment. Participants reported, on average, an increase of just over $40 \%$ in their perceived knowledge about bioethics (it is worth noting that the students did not have access to their initial questionnaires when filling in the post-exercise questionnaires). The individual increases ranged from 1 to 8 out of 10 .

The students' interest in both bioethics and in web authoring increased, but not as dramatically as reported for their bioethics knowledge. This is, in part, a reflection of the higher baseline scores (Table 3), but is also a consequence of some individuals scoring their interest lower after experience of bioethics and/or web authoring than their a priori expectation. The range of changes in interest in bioethics was from -4 to +5 , with 11 of the 69 participants registering lower interest at the end of the exercise, and a further 12 remaining unchanged. Similarly, the changes in interest in web authoring varied from -5 to +5 , with 19 participants reporting less interest after the activity and the interest of a further 15 remained unchanged. 
Bioethics issues identified by participants: On average (mean), students listed 4.1 topics as "bioethics issues" before the exercise in 2002 and 6.6 topics afterwards. This is very similar to the figures in 2003 (3.6 topics before, 7.1 afterwards). Closer analysis of the specific issues cited by the students reveals some interesting trends (see Tables 4 and 5). In both years, cloning was the most prominent issue identified by the students in the a priori surveys. This is reflected not only in the total number of students mentioning the issue (Table 4) but also in the fact that in each year it was the first topic mentioned by approximately half of the students (Table 5). It is interesting to note that the particularly high figure of $89.2 \%$ in January 2003 followed closely after the news reports alleging successful human cloning by the Raelian cult (see, for example, BBC 2002b). This issue is of significantly lower importance to the students after the course, both in terms of the number of mentions and the reduced ranking position relative to other subjects (only 2 students in each year still listed cloning first in their post-exercise questionnaires). Other issues with declining prominence are the most overtly medical topics such as in vitro fertilisation (IVF), euthanasia and abortion, and vaccination (sometimes specifically associated with the MMR vaccine offering protection against Measles, Mumps and Rubella but linked in the popular media with bowel complaints and autism. See, for example, BBC 2001a). GM crops, another stalwart of press coverage of bioethical matters, was also listed less frequently by the students after the module.

As might be expected, the most significant increases in awareness relate to the topics addressed directly in the exercise. For example, students showed high awareness of concern relating to the issue of experiments involving animals before the module (the second most cited topic, after 'cloning', in both a priori surveys), but this increases to over $70 \%$ of students in both cohorts after the activity. The largest single increase for an issue came in 2003 and concerned xenotransplantation, the use of animal-derived organs for human transplants. A remarkable $92 \%$ of students registered this topic as one of their list, with 13 out of 38 in that cohort citing it first. It is worth speculating that this particular prominence is generated by the inclusion of a humorous 
animation in the website reviewing this topic (Mughal et al, 2003). The level of consciousness (over 25\%) about the possibility of using animal organs for transplant in the 2002 a priori questionnaires is also noteworthy. This survey was undertaken shortly after widespread reporting of the cloning of transgenic pigs as a step towards making xenotransplantation a viable route to treatment (see, for example, BBC 2002a). This topic did not rise so strikingly in the psyche of that cohort, for whom the issue was addressed in a guest lecture rather than via the web authoring exercise.

It might have been expected, given that the 'anthrax letters' in the USA had received prominence a matter of weeks earlier (e.g. BBC 2001b), that the 2002 students might have made greater reference to biological warfare in their list of issues. It was, in fact, only mentioned by three students $(8.6 \%)$ that year, and by the same number (equals $8.1 \%$ ) the following year.

\section{DISCUSSION}

A number of arguments can be made for the importance of including a component of ethics education within contemporary biology programmes at undergraduate level, and indeed as part of secondary education. These include the 'carrot' of highlighting the relevance of the subject discipline to items reported in the news media, thereby showing the importance of a good grasp of biology to the broader population. Within the UK, at least, there is also the 'stick' of legislation to include discussion of the ethical implications of our subject within the curriculum.

We report here an exercise which offers the opportunity for students to engage with some contemporary issues in bioethics, whilst at the same time developing a number of important transferable skills, notably teamwork and the ability to produce web pages. Detailed analysis of the impact of the activities upon students in two successive years indicates that they perceive significant increases in both their ability to author websites and in their knowledge about ethical aspects of 
biology. Our surveys indicate that the students do indeed demonstrate awareness of a greater number of bioethics topics after participation in the project. Furthermore, there was a growing maturity not only in the sorts of issues of which they were aware, but also in the scientific terminology they employed. So, for example, we note in 2003 that a priori discussion of "designer babies" and "sex selection" were replaced subsequently by discussion of "pre-implantation genetic diagnosis".

The students' websites generally included reviews of an appropriate range of other online resources. A potential fear prior to the launch of this activity that all groups would end up making links only to the same handful of websites was not, ultimately, substantiated.

This exercise was successful in meeting the intended learning outcomes relating to both generic skills and subject knowledge. This approach can readily be adapted to focus on review of different ethical topics, or indeed the authoring of websites on entirely different subjects. There also exists the possibility to extend the reported activities by, for example, incorporating a requirement for students to write an essay on an issue which was not the focus of their own website, utilising in their research the relevant pages produced by a different team.

\section{REFERENCES}

BBC (2001a) Parents call for MMR vaccine inquiry http://news.bbc.co.uk/1/hi/health/1513108.stm (last accessed, 30th March 2004)

BBC (2001b) FBI pursues anthrax lead http://news.bbc.co.uk/1/hi/health/1586881.stm (last accessed, 30th March 2004) 
BBC (2002a) New pig clones born http://news.bbc.co.uk/1/hi/sci/tech/1738730.stm (last accessed, 30th March 2004)

BBC (2002b) Cloned baby claim met with doubt http://news.bbc.co.uk/1/hi/health/2608655.stm (last accessed, 30th March 2004)

Conway R., Kember D., Sivah A. and Wu M. (1993) Peer assessment of an individual's contribution to a group project. Assessment and Evaluation in Higher Education 18, 45-56.

Mughal W., Kadatcham F., Johnston N. and Evans D. (2003) Xenotransplantation http://www.le.ac.uk/by/cjrw2/archive/xeno/index.htm (last accessed, 30th March 2004)

QAA (2002) Benchmarking academic standards http://www.qaa.ac.uk/crntwork/benchmark/phase2consult.htm (last accessed, 30th March 2004). The benchmarking statement for the biosciences can be reached from that website or directly at http://www.qaa.ac.uk/crntwork/benchmark/phase2/biosciences.pdf

Penman D. and Left S. (2002) MMR Vaccine http://www.guardian.co.uk/theissues/article/0,6512,772073,00.html (last accessed, 30th March 2004) 
Table 1: Learning outcomes of the reported exercise

By the end of the activity, students should be able to:

- Appreciate the science underlying a current controversial development in biomedicine

- Recognise the diversity of informed ethical opinion regarding the development of a current controversial development in biomedicine

- Distinguish the veracity of different web-based resources

- Use web-authoring software, such as Microsoft FrontPage

- Work as a member of a team

- Present their website to their peers 
Table 2: Ethical topics assigned to the groups as the focus of their web sites (2003)

Gene therapy

Genetic patenting

Xenotransplantation $^{+}$

Genetic Screening (including Pre-implantation Genetic Diagnosis)

Use of human material (including foetal tissue)

Use of animals in research and alternatives

Therapeutic cloning and stem cell research

Clinical trials (including use of placebos) $\$$

Healthcare and developing countries*

subject of a guest lecture, not a website, in 2002

$\$$ "use of placebos" in 2002

* "marketing and pricing of pharmaceuticals" in 2002 
Table 3: Evaluation by participants $(n=69$, scores out of 10$)$

\begin{tabular}{|l|c|c|c|}
\hline Category & Before & After & Change \\
\hline Knowledge about bioethics & 2.5 & 6.6 & +4.1 \\
\hline Interest in bioethics & 5.8 & 6.8 & +1.0 \\
\hline Interest in web authoring & 6.1 & 6.5 & +0.4 \\
\hline
\end{tabular}


Table 4: Topics cited by students in questionnaires as "bioethics issues"

\begin{tabular}{|c|c|c|c|c|}
\hline Topic & $\begin{array}{c}2003 \\
\text { before } \\
(\mathrm{n}=37)\end{array}$ & $\begin{array}{c}2003 \\
\text { after } \\
(\mathrm{n}=38) \\
\end{array}$ & $\begin{array}{c}2002 \\
\text { before } \\
(n=35)\end{array}$ & $\begin{array}{c}2002 \\
\text { after } \\
(n=34)\end{array}$ \\
\hline Xenotransplantation & $10.8^{\$}$ & 92.1 & 25.7 & 44.1 \\
\hline Cloning & 89.2 & 29.0 & 77.1 & 50.0 \\
\hline Animal experiments/ testing & 37.8 & 73.7 & 48.6 & 85.3 \\
\hline Use of human tissue/ organs & 2.7 & 73.7 & 5.7 & 44.1 \\
\hline Gene patenting & 0 & 68.4 & 0 & 35.3 \\
\hline Genetic screening & 2.7 & 29.0 & 14.3 & 67.7 \\
\hline Gene therapy & 5.4 & 55.3 & 5.7 & 61.8 \\
\hline Stem cell therapy/ research & 16.2 & 47.4 & 8.6 & 47.1 \\
\hline Pharmaceutical pricing/ marketing* & 0 & 0 & 0 & 47.1 \\
\hline Clinical trials/ Random Controlled trials ${ }^{\#}$ & 5.4 & 44.7 & 2.9 & 2.9 \\
\hline Placebos $^{\#}$ & 0 & 34.2 & 0 & 26.5 \\
\hline Research/ drug sales in third world* & 0 & 34.2 & 2.9 & 0 \\
\hline IVF/ test tube babies & 29.7 & 2.6 & 20.0 & 5.9 \\
\hline GM crops & 13.5 & 2.6 & 28.6 & 11.8 \\
\hline Genetic engineering/ modification $^{+}$ & 27.0 & 26.3 & 14.3 & 11.4 \\
\hline Euthanasia & 27.0 & 0 & 17.1 & 5.9 \\
\hline Embryo/ Foetal research & 2.7 & 5.3 & 8.6 & 23.5 \\
\hline Abortion & 18.9 & 7.9 & 11.4 & 8.8 \\
\hline Designer babies/ Sex selection/ PGD & 13.5 & 10.5 & 17.1 & 0 \\
\hline Vaccination/MMR & 5.4 & 0 & 17.1 & 2.9 \\
\hline
\end{tabular}

${ }^{\$}$ figures quoted as $\%$ of cohort. Only topics cited on at least one occasion by $10 \%$ or more of a cohort have been included

${ }^{+}$excluding specific reference to GM crops (listed separately)

* Topic switched from "pharmaceutical marketing and pricing" in 2002 to "healthcare and developing countries" in 2003

\# Topic switched from "use of placebos" in 2002 to "clinical trials (inc use of placebos)" in 2003 
Table 5: Topics identified in first place by more than one student

\begin{tabular}{|l|l|l|l|}
\hline \multicolumn{1}{|c|}{$\mathbf{2 0 0 3}$ before } & \multicolumn{1}{|c|}{$\mathbf{2 0 0 3}$ after } & \multicolumn{1}{c|}{$\mathbf{2 0 0 2}$ before } & \multicolumn{1}{c|}{ after } \\
\hline Cloning (19) & Xenotransplantation & Cloning (16) & Gene therapy (7) \\
Animal expts (5) & $(13)$ & Animal expts (4) & Animal expts (5) \\
Euthanasia (3) & Use of stem cells & Genetic & Xenotransplantation \\
Abortion (2) & $(5)$ & Engineering/ & (4) \\
Drug testing (2) & Gene therapy (4) & Modification (3) & Genetic screening (5) \\
Genetic & Gene patenting (3) & Xenotransplantation & Gene patenting (3) \\
Engineering/ & Animal expts (2) & $(3)$ & Cloning (2) \\
Modification (2) & Cloning (2) & Euthanasia (2) & Use human tissue \\
& Clinical trials (2) & & Respect for religious \\
& Use of human & & views (2) \\
& tissue (2) & & \\
& & & \\
\end{tabular}




\section{Box 1: Student feedback on the initial training exercise}

I have never tried any thing like this before and I could actually do it, which I didn't expect!

I think this was a very useful exercise with the instructions being very clear and easy to follow. It has given me more of an idea of how to go about starting this assignment because before I wouldn't have had a clue as to where to start.

A good introduction to creating a website. Didn't know anything about it before today!

I appreciated having the intro lecture before tackling the problem on the computer!

Prior to today's 'hands on' experience, I was absolutely petrified of undertaking this exercise. I thought it was, for me, a little farcical (I don't really like computers and thought it'd be totally out of my league!!). I have actually enjoyed this and will now enjoy the ethics webpage-making exercise.

This was the first opportunity for me to find out how to make design a website (sic). The lecture and the exercise went well together as they complimented each other. The lecture allowed the topic to be introduced and gave some background about the exercise so we were not led into it "blind."

This was a very helpful and fun exercise:-)

I have always been interested in learning how to write websites and this session has helped me to get to grips with the basics that we will need in producing the website for our assessment. I think it was a very worthwhile exercise.

This exercise was VERY helpful as I normally struggle to turn the monitor on, let alone write a web page.

Good point about the preview and normal pages from before. I thought I had lost my first page but it was because I was in preview rather than normal.

I didn't really know much about making a web site but after the lecture I felt fairly confident. This exercise has re-enforced that well.

I'd always thought that designing a web page would be a very difficult thing, but the step-by-step instructions made the hole (sic) thing very painless and easy to understand. The lecture last week was a great introduction to web-design, so that coming to this practical, I had some idea what I was doing. Thanks v. much $\mathrm{A}^{*}$

I'm hopeless with computers (its a mutual understanding... I hate them, they hate me) but I think I have actually managed to make this work! Will also find this very useful when we start doing our own website.

The combination of lecture and exercise worked very well as it meant I had a basis of understanding before I started.

This was a very useful exercise because I had no idea before where to start if I wanted to design a web page, but it is something that I wanted to be able to do. 